\title{
Studies of the Activation Steps Concurrent to Ligand Binding in $\delta O R$ and KOR Opioid Receptors Based on Molecular Dynamics Simulations
}

\author{
Michal Kolinski ${ }^{1}$ and Slawomir Filipek ${ }^{*}, 1,2$ \\ ${ }^{1}$ International Institute of Molecular and Cell Biology, 4 Trojdena St, 02-109 Warsaw, Poland \\ ${ }^{2}$ Faculty of Chemistry, Warsaw University, 1 Pasteur St, $02-093$ Warsaw, Poland
}

\begin{abstract}
Although agonists and antagonists occupy the same space in opioid receptors the agonists only are able to evoke their activation and different agonists may lead to different conformational states of the receptor. Agonist binding is the first step in ligand-induced receptor activation which proceeds through series of conformational changes. To investigate the relationship between the final movements of a ligand in a receptor binding site and the first steps of the activation process in $\delta \mathrm{OR}$ and $\kappa O R$ opioid receptors we chose a set of rigid ligands with the structural motif of tyramine. On the basis of conducted molecular dynamics simulations we propose that, similarly as in the case of $\mu$ OR [Kolinski and Filipek, TOSBJ 2008], agonists and antagonists bind to Y3.33 but only agonists are able to move deeper into the receptor binding site and to reach H6.52. The movement from Y3.33 to H6.52 induces breaking of the TM3-TM7 connection ("3-7 lock"). However, conversely to morphine (previous paper) butorphanol did not induce breaking of this connection in a single movement but instead a time of about $20 \mathrm{~ns}$ was required and this process was composed of a series of separation and joining events. We also observed a concerted motion of W6.48 and H6.52 suggesting existence of an extended "rotamer toggle switch". Simultaneous action of both switches, the "3-7 lock" and the "rotamer toggle switch", implies a temporal but also spatial (an agonist linking H6.52 and D3.32) dependence between them.
\end{abstract}

Keywords: Molecular dynamics, homology modeling, G protein coupled receptors, opioid receptors, molecular switches.

\section{INTRODUCTION}

G protein coupled receptors (GPCRs) interact with very diverse sets of ligands which bind to the transmembrane segments and sometimes also to the receptor extracellular domains. Each receptor subfamily undergoes a series of conformational rearrangements leading to the binding of a $\mathrm{G}$ protein during the activation process. All GPCRs preserved the 7-TM scaffold during evolution but adapted it to different sets of ligands by structure customization. Binding of structurally different agonists requires the disruption of distinct intramolecular interactions, leading to different receptor conformations and differential effects on downstream signaling proteins. The dynamic character of GPCRs is likely to be essential for their physiological functions, and a better understanding of this molecular plasticity could be important for drug discovery $[1,2]$.

Experiments suggest that agonist binding and receptor activation occur through a series of conformational intermediates. Transition between these intermediate states involves the disruption of intramolecular interactions that stabilize the basal state of a receptor. Such profound changes are evoked by the action of molecular switches. The switches proposed so far for different GPCRs include the "rotamer toggle

*Address correspondence to this author at the International Institute of Molecular and Cell Biology, 4 Trojdena St, 02-109 Warsaw, Poland; Tel: (48-22) 5970-722; Fax: (48-22) 5970-715; E-mail: sfilipek@iimcb.gov.pl switch" involving the CWxPxF sequence on TM6 [3], the switch based on the $\operatorname{NPxxY}(\mathrm{x})_{(5,6)} \mathrm{F}$ sequence linking TM7 and H8 [4], the "3-7 lock" interaction connecting TM3 and TM7 (involving Schiff base-counterion interaction in rhodopsin) [5, 6], and the "ionic lock" linking transmembrane helices TM3 and TM6 and employing the E/DRY motif on TM3. In the rhodopsin structure all these switches are closed (inactive state), however, in the recent crystal structures of $\beta_{1}$ - and $\beta_{2}$-adrenergic receptor complexes with antagonists and inverse agonists the "ionic lock" is open while the "rotamer toggle switch" remains closed. To explain this effect it has been proposed [7] that such configuration of switches allows for $\beta$-arrestin signaling independent of a $G$ protein $[8,9]$. The same configuration of switches was found in a newly crystallized adenosine $A_{2 a}$ receptor $\left(A_{2 a} R\right)$.

The first crystallized GPCR was rhodopsin in 2000 [10]. Several years later, owing to the progress in crystallization techniques, new crystal structures emerged, namely those of $\beta_{1}$ - and $\beta_{2}$-adrenergic receptors $\left(\beta_{1} \mathrm{AR}\right.$ [11] and $\beta_{2} \mathrm{AR}$ [12$14])$ and of adenosine receptor $\left(A_{2 a} R\right.$ [15]). All these receptors belong to the same family of GPCRs (family A: Rhodopsin-like, and also Rhodopsin group in the GRAFS classification system based on phylogenetic studies [16]) and their structures are very similar in the transmembrane region. The opioid receptors also belong to the same family of GPCRs [17]. They are located in the membrane of neurons of the central nervous system and of some types of smooth muscle cells. For the important role they play in the human 
body in controling pain and stress, modulating immune responses and developing addiction the opioid receptors were subject of numerous investigations (reviews [18-20]). There are four types of opioid receptors: $\mu \mathrm{OR}, \delta \mathrm{OR}, \kappa \mathrm{OR}$ and the nociceptin/opioid receptor-like 1 . There are also additional, pharmacologically classified, subtypes of opioid receptors but it is believed that they may, at least partly, originate from homodimerization of the four main opioid receptor types and their heterodimerization with other GPCRs [21]. Like many other GPCRs opioid receptors undergo dimerization and may be engaged in cross-signaling as shown recently for the $\alpha_{2 \mathrm{~A}}$-AR and $\mu \mathrm{OR}$ heterodimer [22] as well as for $\delta \mathrm{OR}-\kappa \mathrm{OR}[23,24]$. Knowledge of the structural details of receptor activation is absolutely necessary in order to design new drugs with precise action and negligible side effects.

Theoretical methods, including homology modeling and molecular dynamics (MD) simulations, can help to derive 3dimensional models of opioid receptors for elucidation of activation processes and also for usage in structure-based drug design $[25,26]$. Pharmacophores of several opioid ligands are presented in a review [20] in an effort to classify the structural requirements for ligand binding and selectivity. Modeling studies of $\delta \mathrm{OR}$ and $\mathrm{KOR}$ were reported in several papers. Iadanza et al. [27] docked a synthetic ligand to KOR with subsequent $\mathrm{MD}$ using an earlier model of the opioid receptor binding site [28]. Aburi et al. [29] built a model and simulated in the membrane the unliganded human $\delta O R$. Pogozheva et al. [30] reviewed homology modeling attempts using experimental constraints to build three types of opioid receptors based on the rhodopsin template with subsequent docking of agonists and antagonists. However, no simulations were performed to investigate coupling of ligand movements in a receptor-binding site with an activation pathway.

In our previous paper we investigated structural changes of $\mu \mathrm{OR}$ occurring upon ligand binding in the binding pocket and associated them with the early activation steps in this receptor [31]. It was found that both agonists and antagonists entered the crevice between positions 3.33 and 6.52 (numbers according to Ballesteros-Weinstein numbering scheme [32]) but antagonists tended to bind to Y3.33 whereas agonists to H6.52. During the molecular dynamics simulation it was possible to observe a break of a hydrogen bond D3.32-Y7.43 linking TM3 and TM7 ("3-7 lock") in complexes with agonists and also in the complex with a restrained antagonist, naltrexone, forced to act as an agonist. To confirm earlier results and to find possible differences in the activation process evoked by a larger agonist butorphanol (compared to morphine described in our previous paper) we performed a study in two other opioid receptors, $\delta \mathrm{OR}$ and KOR. As before we used structurally similar and mostly rigid nonpeptide ligands. They are built on a tyramine ( $\mathrm{p}$ hydroxyphenethylamine) scaffold so the two parts, the "message" (tyramine) and the "address" [33], are well distinguished. Peptide or peptide-derived ligands were not used because their flexibility would obscure the very first structural movements induced upon ligand binding, provided the activation scheme is similar. Similarly to earlier results a time dependence between the action of the "3-7 lock" and the "rotamer toggle switch" was also observed.

\section{METHODS}

\section{Modeling Unliganded Opioid Receptors and Simulating in the Membrane}

Modeling the structure of $\delta \mathrm{OR}$ and $\kappa \mathrm{OR}$ opioid receptors was done on the basis of the crystal structure of inactive rhodopsin with no gaps (Protein Data Bank code 1U19) [34] and also on the basis of the structure of $\beta_{2}$-adrenergic receptor (Protein Data Bank code 2RH1) [12]. The amino acid sequences of human opioid receptors were obtained from the Swiss-Prot database (codes: P41143 and P41145 for $\delta \mathrm{OR}$ and $\kappa \mathrm{OR}$, respectively). The Clustal $\mathrm{W}$ algorithm [35] was employed for aligning the multiple sequences and the resulting alignment is shown in Fig. (1) in the supporting material. The most conserved residues as well as the conserved motifs of GPCRs: E/DRY, CWxPxF and $\operatorname{NPxxY}(\mathrm{x})$ were aligned in all transmembrane helices. There is, however, a discrepancy in the aligning of the loop between TM4 and TM5 (ECL2). The automatic alignment prefers narrower gaps and in both adrenergic receptors and $\mathrm{A}_{2 \mathrm{a}} \mathrm{R}$ it aligns cysteine residues not corresponding to those forming the disulfide bridge in rhodopsin. Such incorrect alignment was shown in a recent paper [36], however, the results were not affected because this alignment was done for comparison purposes only. These cysteines are engaged in formation of other disulfide bridges (two of them are marked in adrenergic receptors in Fig. (1) in the supporting material). For this reason homology modeling was done using a manually corrected alignment (as in our earlier paper [31]). The cysteine residues forming a connection in the same position as in the rhodopsin structure are marked in red.

Homology modeling was done employing Modeller [37, $38]$ and using rhodopsin and $\beta_{2} \mathrm{AR}$ structures as templates. Since the N-termini of $\beta_{2} \mathrm{AR}$ and $\beta_{1} \mathrm{AR}$ are not detected in the crystal these parts were not modeled when the $\beta_{2} \mathrm{AR}$ structure was used as a template. In both opioid receptor models the palmitoyl chain was added to cysteine at the end of the cytoplasmic helix H8 (positions 333 and 345 for $\delta \mathrm{OR}$ and $\kappa \mathrm{OR}$, respectively). Then, each receptor model was inserted into the lipid bilayer composed of DPPC (dipalmitoyl-phosphatidylcholine). The membrane containing 128 phospholipids (64 in each layer) was surrounded by water molecules in a periodic box $(6.4 \mathrm{~nm} \times 6.4 \mathrm{~nm} \times 9.5 \mathrm{~nm})$. Excessive lipid molecules were removed and counterions were added to make the whole system neutral. Before inserting the receptor the membrane was equilibrated for 20 ns. Details of building the receptor models and the membrane are the same as described previously in [31]. All minimizations and simulations were performed using Gromacs (v. 3.3) [39]. A standard ffgmx forcefield with additional parameters for lipids [40] and water SPC [41] was used for more accurate treatment of hydrogen bonds. The PME procedure [42] was applied for treatment of the longrange electrostatic interactions. After energy minimization of the receptor-membrane system the three step simulations were performed. During the first step, lasting $1 \mathrm{~ns}$, all backbone atoms were restrained to their initial positions, hydrogen bonds were also restrained using the LINCS algorithm [43]. In the second step (2 ns) restraints were removed from both termini and from all loops of the receptors. In the third step (lasting $20 \mathrm{~ns}$ ) all restraints were 
(a)

\section{$\delta \mathrm{OR} / \mathrm{Rh}$}

(b) $\kappa \mathrm{OR} / \mathrm{Rh}$

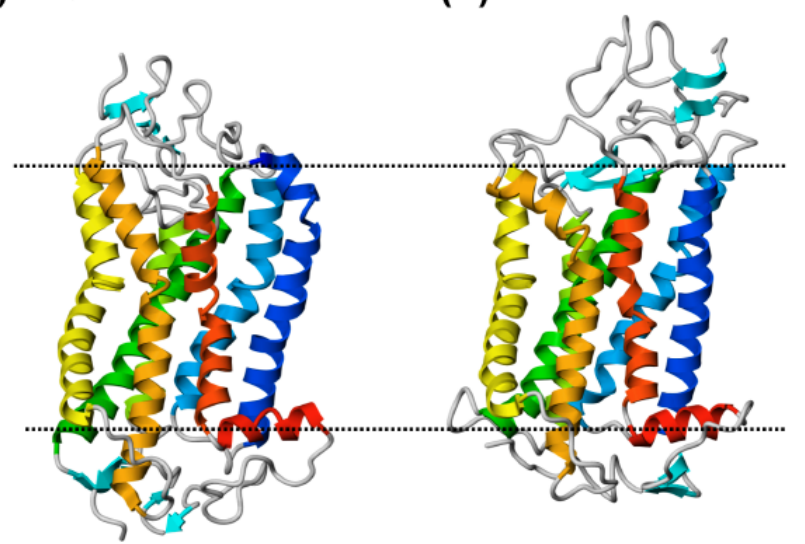

(c)

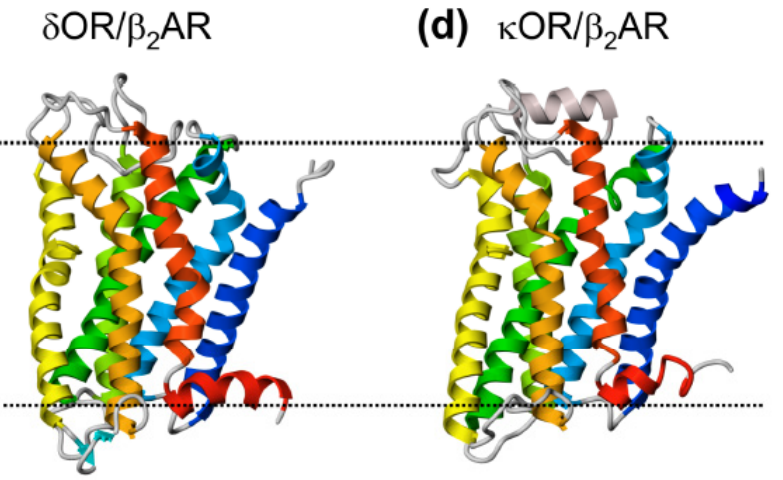

Fig. (1). The structures of $\delta \mathrm{OR}$ and $\kappa \mathrm{OR}$ opioid receptor models based on different templates: (a) $\delta \mathrm{OR}$ on Rh template; (b) $\kappa \mathrm{OR}$ on Rh template; (c) $\delta \mathrm{OR}$ on $\beta_{2} \mathrm{AR}$ template; (d) $\kappa \mathrm{OR}$ on $\beta_{2} \mathrm{AR}$ template. Transmembrane helices are colored according to rainbow color scheme: TM1 in blue, TM2 in light blue, TM3 in green, TM4 in yellow-green, TM5 in yellow, TM6 in orange, TM7 in red. Lines indicate borders of the membrane and were derived from average positions of the phosphorus atoms in phospholipids.

released. For checking the quality of obtained models the Procheck program $[44,45]$ was used.

\section{Modeling of Ligand-Receptor Complexes}

The "ionic lock" in the $\beta_{2}$ AR structure is in an open state (similarly as in $\beta_{1} \mathrm{AR}$ and $\mathrm{A}_{2 \mathrm{a}} \mathrm{R}$ ) what may suggest that the structure is activated to some extent or, alternatively, that it takes part in another type of signaling independent of a $G$ protein. Since we studied the initial movements in the receptor-binding site and none of the analyzed ligands signal via arrestin the opioid receptor models based on the rhodopsin template were used for ligand docking. The ligands were constructed in their protonated-nitrogen forms. The RESP method [46] was applied for calculation of ligand atomic charges. First, the geometry of small molecules was optimized to determine the stable minimum and the Molecular Electrostatic Potential (MEP) was calculated using the Hartree-Fock procedure employing the $6-31 \mathrm{G}^{*}$ basis set in Gaussian (v.03 rev. C.02 Gaussian Inc.). Then the RESP program was used for fitting atom-centered charges according to the MEP of modeled ligands. The ligands were inserted in the middle of the binding pocket to preserve the interaction between D3.32 and the protonated amine nitrogen atom present in all ligands. Phenolic $\mathrm{OH}$ groups of all analyzed antagonists were initially positioned in the space between TM3 and TM6 so as not to force any specific location and to meet spatial requirements of other parts of the ligand (especially the bulky "address" part). In order to sample different possibilities of binding in the binding cavity of the receptor all created complexes were subjected to the simulated annealing procedure in Yasara (v.8.2, Yasara Biosciences) with the Yamber2 forcefield [47] at the temperature diminishing from $900 \mathrm{~K}$ to $0 \mathrm{~K}$ whereas the length of the cycle was variable. During this procedure the ligand and the side chains of amino acids within $1.0 \mathrm{~nm}$ vicinity were allowed to move. The simulated annealing procedure was restarted several times with the initial positions of ligands in the binding site modified manually while preserving the salt bridge between the charged amine group of a ligand and the carboxyl group of D3.32. The optimized complexes were inserted into the DPPC membrane (taken from $20 \mathrm{~ns}$ simulations of empty opioid receptor) and subjected to $\mathrm{MD}$ simulations. In the first 100 ps simulation the restraints were imposed on the transmembrane (TM) part of the backbone of each receptor. In the second step of MD, lasting $10 \mathrm{~ns}$, all restraints were removed. To check the binding modes for a true agonist we performed the same procedure of docking for butorphanol. In this case, because of a longer time required for breaking the "3-7 lock", we extended the last part of MD simulation (without restraints) up to $21 \mathrm{~ns}$.

The Modeller and Clustal W programs were used within the Discovery Studio (Accelrys Inc., v.2.0). Animations (in the supporting material) were created in VMD [48]. 


\section{RESULTS AND DISCUSSION}

\section{Characterization of Obtained Receptor Models}

Using homology modeling procedure based on rhodopsin (Rh) and $\beta_{2} \mathrm{AR}$ structural templates we constructed two models of each opioid receptor - $\delta \mathrm{OR}$ and $\kappa \mathrm{OR}$. Their structures, after $20 \mathrm{~ns}$ of molecular dynamics, are shown in Fig. (1). The bundle of seven transmembrane helices and an additional amphiphilic helix $\mathrm{H} 8$ are present in all models. The characteristic bends on TM6 and TM7 preserving the shape of these helices are still present and are located in the same positions as in the templates. However, helix TM7 is one turn longer in $\delta \mathrm{OR}$ and $\mathrm{KOR}$ models based on the $\beta_{2} \mathrm{AR}$ template than in receptors modeled after the $\mathrm{Rh}$ template. The first turn of the extracellular end of TM7 in Rh is slightly distorted in the rhodopsin crystal structure (PDB id 1U19) and during MD of opioid receptor models it unwinds and contributes to the ECL3 loop. The overall shape and bends are also preserved in TM2. Helices TM3 and TM4 are straight both in templates and in opioid receptor models. An interesting case is TM5. There is no bend on this transmembrane helix in the rhodopsin structure and only one bend in $\beta_{1}$ - and $\beta_{2} A R$. However, in $\delta O R$ models based on each of these templates there are two bends on this helix (Fig. 1a and Fig. 1c), whereas there is only one such bend on TM5 in אOR models regardless of the template (Fig. 1b and Fig. 1d). The extracellular end of TM1 is bent toward the center of the protein in the $\mathrm{Rh}$ template but it is directed outward (via a smooth kink or arch) in both adrenergic receptors. The kink in the middle of TM1 present in $\mathrm{Rh}$ disappeared in $\delta \mathrm{OR}$ and $\kappa \mathrm{OR}$ models based on the $\mathrm{Rh}$ template (there is a kink on this helix in $\delta \mathrm{OR}$ but very close to the extracellular surface and in fact it is composed of amino acids belonging mostly to the $\mathrm{N}$-terminus). The outward smooth kink on TM1 in $\delta O R$ and $\kappa O R$ models based on the $\beta_{2} \mathrm{AR}$ template corresponds to the kink in the template and it is even more bent due to extensive contact between the end of this helix and the charged part of the bilayer (N-terminus was not constructed in these models so it did not stabilize the position of the extracellular end of this helix).

The RMSD plots for the unconstrained $20 \mathrm{~ns}$ of MD simulation calculated for all receptors are shown in Fig (2). The values for all opioid receptor models stabilized in a $0.20-0.25 \mathrm{~nm}$ range starting from $14 \mathrm{~ns}$ of the simulation attesting to model stability. $20 \mathrm{~ns}$ MD simulation was able to reveal characteristic features of the transmembrane part of both opioid receptors which are either absent in the respective templates or present in only one of them (bends of TM5). The resemblance of structures based on different templates may be due to the influence of phospholipids since they are very flexible and force the transmembrane bundle of helices to pack according to their sequences. The similarity of structures is also partially achieved for the longest extracellular loop linking TM4 and TM5 (ECL2) in both $\delta \mathrm{OR}$ models. There is no secondary structure of this loop in models based on either template (Fig. 1a and Fig. 1c). The helix present in the initial structure of the $\beta_{2} \mathrm{AR}$ template lost its $2 \mathrm{D}$ arrangement and moved toward the binding cavity of the receptor. The $\beta$-sheet in ECL2 of the Rh template also lost its secondary structure but this loop remained in nearly the same position as in the template. Similarly, the ECL2 loop of $\mathrm{A}_{2 \mathrm{a}} \mathrm{R}$ receptor does not exhibit $2 \mathrm{D}$ structure elements either. On the other hand, in both $\kappa O R$ models the secondary elements were preserved ( $\beta$-sheet in $\mathrm{Rh}$ and a helix in $\left.\beta_{2} \mathrm{AR}\right)$. Changing the secondary structure and position of ECL2 requires large simulation time scale and, therefore, was not completed during $20 \mathrm{~ns}$ of MD in any of the models although in some cases the extracellular and cytoplasmic caps were markedly different from the initial structures. The $\mathrm{N}$ - and $\mathrm{C}$ - termini were retained in opioid receptor structures based on the rhodopsin template to preserve structure integrity. Since they did not affect ligand binding such procedure was fully justified for this kind of investigations.

\section{Binding Modes of Opioid Receptor Ligands}

In order to explore the effect of ligand binding on the structure of opioid receptors we used typical ligands of $\delta \mathrm{OR}$ and KOR: naltrexone (NTX - nonselective antagonist), naltrindole (NTI - $\delta$ OR selective antagonist), norbinaltorphimine

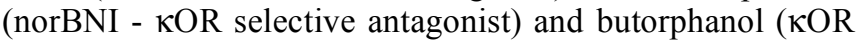
selective agonist) (Fig. 3). All ligands were analogs of morphine with an identical structural motif of tyramine which is present in most of the nonpeptide opioids. To study the final movements of the ligand in the binding site and the concurrent activation steps of opioid receptors it was necessary to use opioid receptor models based on the crystal structure of an inactive receptor. In this respect the configuration of switches in crystallized $\beta_{1} A R, \beta_{2} A R$ and $A_{2 a} R$

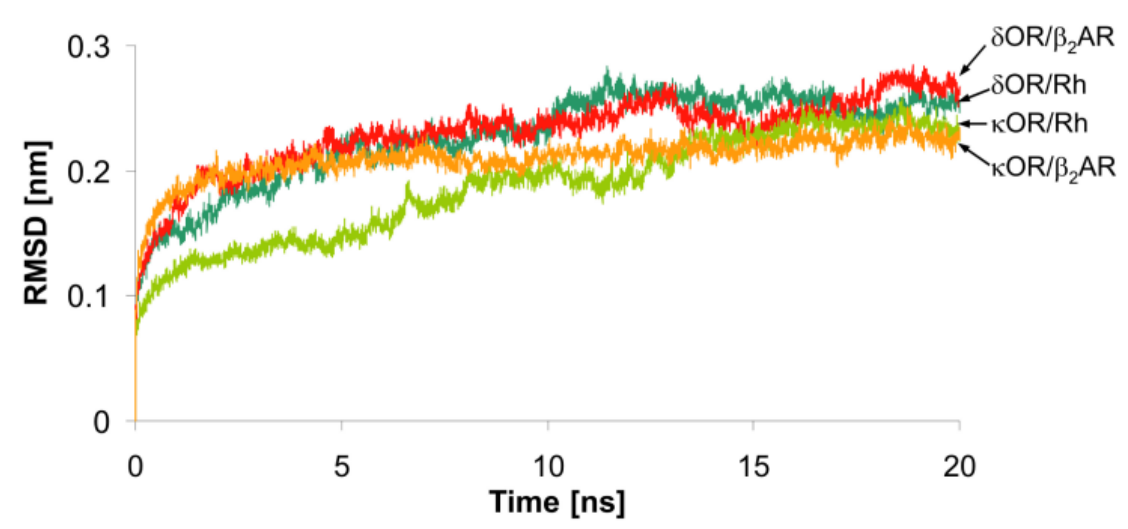

Fig. (2). The root mean square displacement (RMSD) plots for unconstrained MD simulations of unliganded opioid receptor models: $\delta O R$ on $\mathrm{Rh}$ template in dark green, $\kappa \mathrm{OR}$ on $\mathrm{Rh}$ template in light green, $\delta \mathrm{OR}$ on $\beta_{2} \mathrm{AR}$ template in red; and $\kappa \mathrm{OR}$ on $\beta_{2} \mathrm{AR}$ template in orange. 


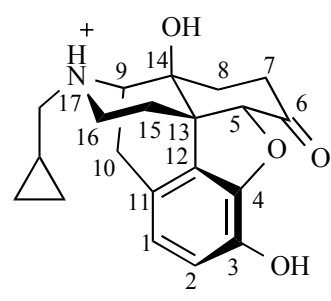

Naltrexone (NTX) antagonist nonselective

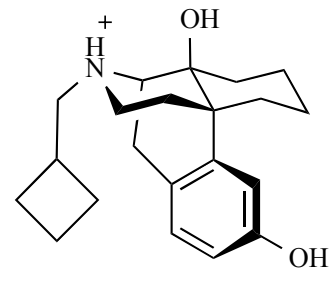

Butorphanol agonist selective

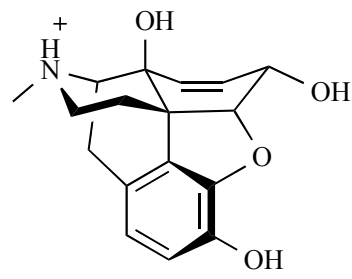

Morphine agonist selective

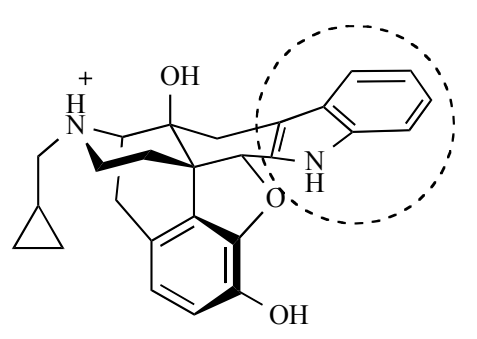

Naltrindole (NTI)

antagonist selective

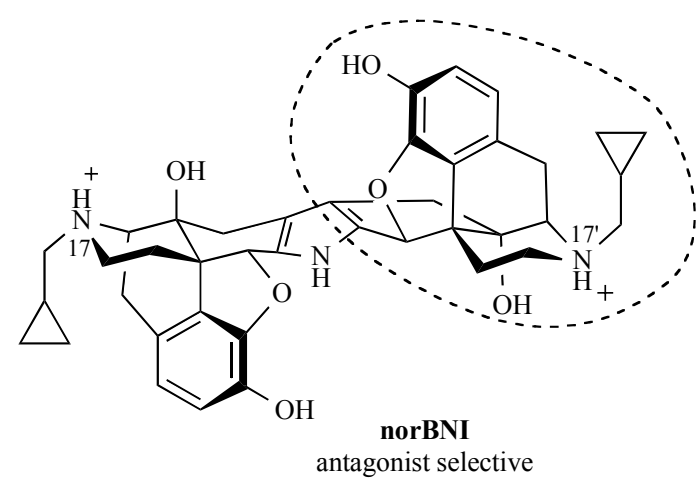

Fig. (3). Structural formulas of ligands used in this study and a structure of morphine for comparison purposes. Numbering of atoms is shown for the first compound. Dashed ellipses denote the so called "address" part of selective antagonists.

suggests that some activation steps (or other rearrangements evoked by the inverse agonist bound) have already been completed. Based on virtual screening results [36] and also on data from a long $\mathrm{MD}$ simulation of $\beta_{2} \mathrm{AR}$ [49] it was postulated that docking of agonists e.g. epinephrine (which is smaller than the ligand in the crystal structure) requires changes in the positions of transmembrane helices resulting in the shrinkage of the binding site. There is also another hypothesis that crystal structures of adrenergic receptors are prepared for arrestin signaling, especially that the $G$ protein binding site is blocked by interaction of ICL2 (loop between TM3 and TM4) with the DRY motif on TM3 [7]. In opioid receptors the agonists and antagonists are frequently of the same shape (especially the "message" part" which is responsible for the activation of the receptor). Due to all these reservations concerning crystallized adrenergic receptors structures for all subsequent investigations we used models of opioid receptors based on the rhodopsin structure.

The ligands were manually inserted into the binding pocket of the receptor close to the carboxyl group of D3.32 to set an interaction with the protonated nitrogen atom $\left(\mathrm{N}_{17}\right)$ in the tyramine structure. This ionic interaction is known to exist in the case of all amine ligands of opioid receptors. The phenolic $\mathrm{OH}$ group of all analyzed ligands was initially placed in the space between TM3 and TM6 and the ligands together with adjacent amino acids were subjected to simulated annealing procedure. This initiated a gradual adjustment between a ligand and a receptor resulting in an induced fit of both structures. Especially the ECL2 loop was gradually changing its structure in both models (mostly moving toward the extracellular side of the protein) when antagonists NTI or norBNI were docked. Therefore, the second aim of the simulated annealing procedure was to find a more suitable position of this loop. Clustering of the final ligand positions revealed two distinct binding modes for the ligands. In most cases the ligands established a hydrogen bond with Y3.33 but there were also some ligands (agonist butorphanol and to some extent also the unselective antagonist NTX) positioning themselves close to and interacting with H6.52. The final binding positions of all ligands were found between three transmembrane helices TM3, TM6 and TM7.

\section{Binding of Antagonists}

The location of selective antagonists, NTI and norBNI, in the binding pocket of the receptor is shown in Fig. (4a) and Fig. (4b). The charged amine group of the ligand interacts with D3.32 and the phenolic $\mathrm{OH}$ group is bound to the $\mathrm{OH}$ group of $\mathrm{Y} 3.33$. The second $\mathrm{OH}$ group $\left(\mathrm{C}_{14}\right)$, present in all analyzed ligands, forms a hydrogen bond with the carboxyl group of D3.32. The aromatic ring of NTI in the "address" part is hidden in a hydrophobic pocket flanked by amino acids located at the extracellular ends of TM6 and TM7 and also by the second extracellular loop (ECL2). NorBNI was the biggest of analyzed ligands and the only one possessing two protonated nitrogen atoms. $\mathrm{N}_{17}$ interacts with D3.32 and $\mathrm{N}_{17}$, with E6.58 (present only in $\kappa \mathrm{OR}$ which makes this compound highly selective for $\kappa \mathrm{OR}$ ). The unselective antagonist, naltrexone (NTX), is also stably bound to $\delta \mathrm{OR}$ and $\mathrm{KOR}$ in the same mode as the selective antagonists, i.e. the amine group of NTX is bound to D3.32 and the phenolic $\mathrm{OH}$ group to Y3.33. NTX does not contain the "address" part so it does not bind to the extracellular loops of the receptor which are regarded as determinants of ligand selectivity. All hydrogen bonds in the amino acids surrounding the ligand were preserved during $10 \mathrm{~ns}$ simulations for all analyzed complexes of antagonists. During the simulated annealing procedure NTX was seldom found close to another residue, H6.52, but it could be a result of an increased temperature and higher fluctuations. NTX moved back to Y3.33 when temperature was diminished. The selective antagonists, 

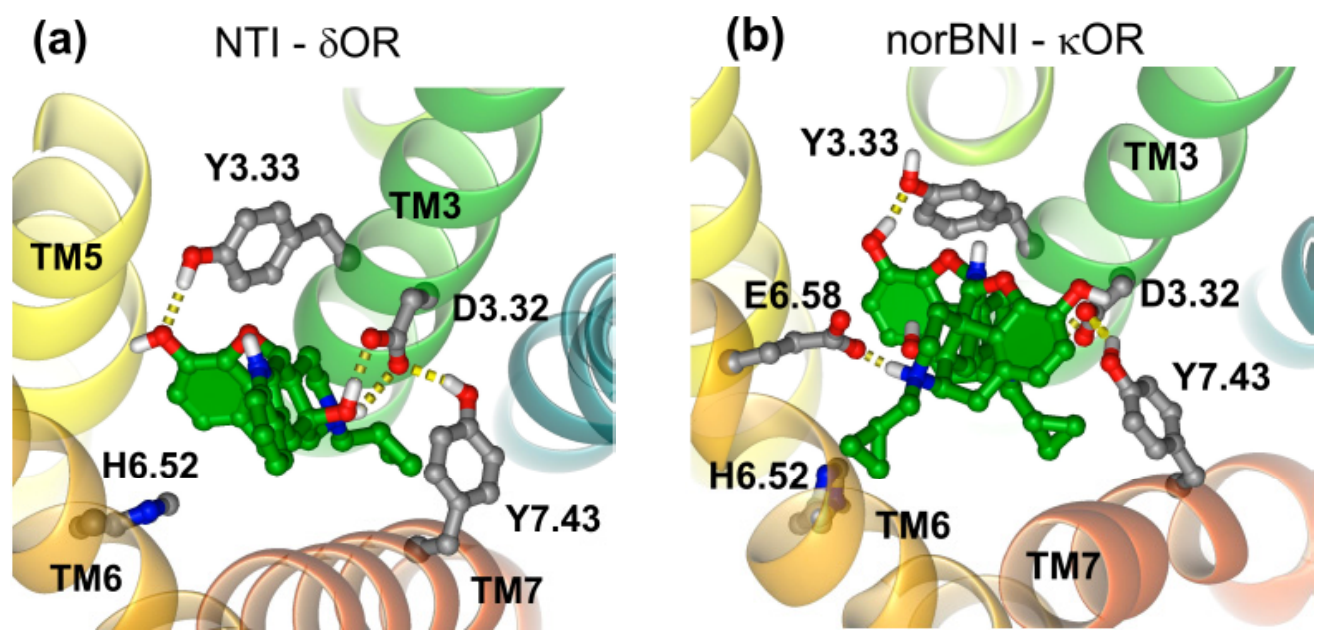

Fig. (4). The structure of the binding pocket of (a) NTI- $\delta$ OR complex, and (b) norBNI- $\kappa O R$. View from the extracellular side. Phenolic rings of both ligands are filled.

because of their bulkier structures, were stably bound to Y3.33 even at higher temperature. The fragments of MD simulations of the NTI- $\delta$ OR, norBNI- $\kappa O R$, NTX- $\delta$ OR and NTX-кOR complexes are shown in the supporting material (Animations 1-4, respectively).

\section{Binding of an Agonist - Butorphanol}

During the preliminary simulated annealing procedure butorphanol formed a hydrogen bond between its phenolic $\mathrm{OH}$ group and H6.52 (contrary to antagonists which interacted with Y3.33) for most of the time. The same behavior

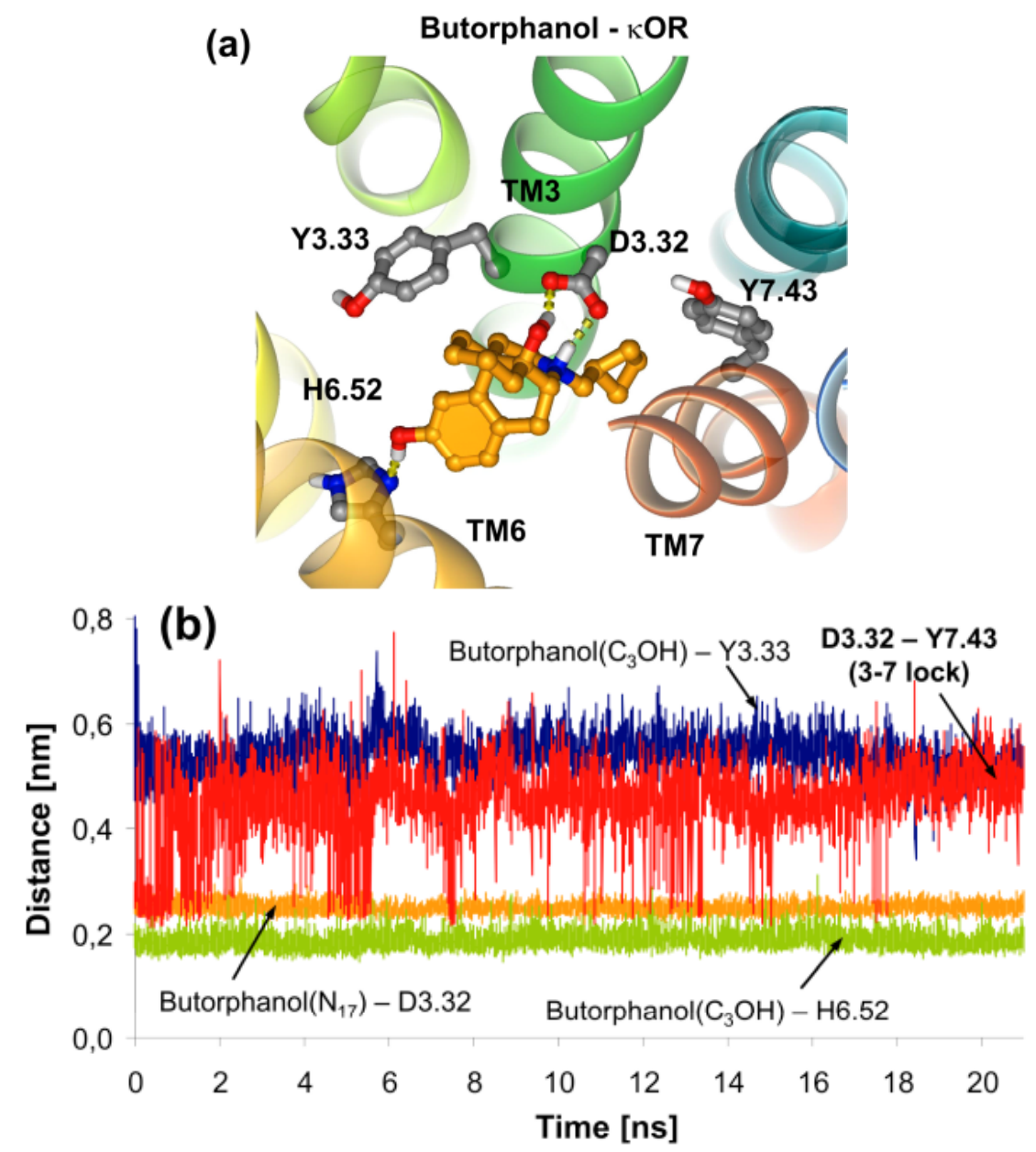

Fig. (5). (a) The structure of the binding site of butorphanol-кOR complex at the end of $21 \mathrm{~ns}$ MD simulation. View from the extracellular side. (b) Plots of the distances D3.32-Y7.43 (red), butorphanol-Y3.33 (dark blue), butorphanol-D3.32 (orange) and butorphanol-H6.52 (green) from MD simulation of butorphanol-KOR complex. 
was observed by us in the case of agonists (morphine and Nmethyl-morphine) studied in $\mu$ OR [31]. To investigate the influence of butorphanol on the receptor structure the MD simulation was performed starting from the structure established after the simulated annealing procedure. The most distinctive part of butorphanol structure is a cyclobutane ring which is located, as are the cyclopropane rings of other studied compounds, close to residues D3.32 and Y7.43 (which form a hydrogen bond linking transmembrane helices TM3 and TM7) and to tryptophan W6.48. This location is between helices TM3, TM6 and TM7 directly in the center of a receptor. Similarly to the action of agonists of $\mu \mathrm{OR}$ we expected to see breaking of the D3.32-Y7.43 hydrogen bond ("3-7 lock"), what in fact happened (Fig. 5a and Fig. 5b). In the case of morphine this break occurred in a single event at $1.5 \mathrm{~ns}$ of MD simulation but for $N$-methyl-morphine the bond was initially broken at $0.5 \mathrm{~ns}$ but after $4 \mathrm{~ns}$ it started to recover and the "3-7 lock" was flickering [31]. Therefore, we decided to perform longer MD simulation which was extended up to $21 \mathrm{~ns}$ (Fig. 5b). Several distances were monitored during the simulation including the "3-7 lock" and distances between a ligand and key residues of the receptor, D3.32, Y3.33 and H6.52. During the whole simulation the phenolic group of butorphanol was firmly bound to H6.52 but the D3.32-Y7.43 hydrogen bond was flickering and the "3-7 lock" broke definitively after $18 \mathrm{~ns}$ of the simulation. A more bulky substituent (cyclobutane ring), which was located very close to the D3.32 and Y7.43 residues did not seem to contribute to the disruption of the hydrogen bond between them, so the hydrophobic entity in this location, present in nearly all antagonists based on tyramine, in fact stabilizes the structure of the receptor. However, the lack of two oxygen atoms (in comparison to NTX) makes this ligand more hydrophobic and movable enabling it to form a bond with H6.52 located deeper in the receptor structure. A fragment of MD simulation of the butorphanol-kOR complex illustrating breaking of the "3-7 lock" is shown in the supporting material (Animation 5).

\section{Binding of an Antagonist, NTX, Restrained to Bind in Agonist Mode}

To check the possibility that formation of a bond with H6.52 (accompanied by a rotation of a ligand toward a receptor center) is responsible for the break of the "3-7 lock" we performed restrained MD simulations of NTX. Only this antagonist was used to study the forced binding to opioid
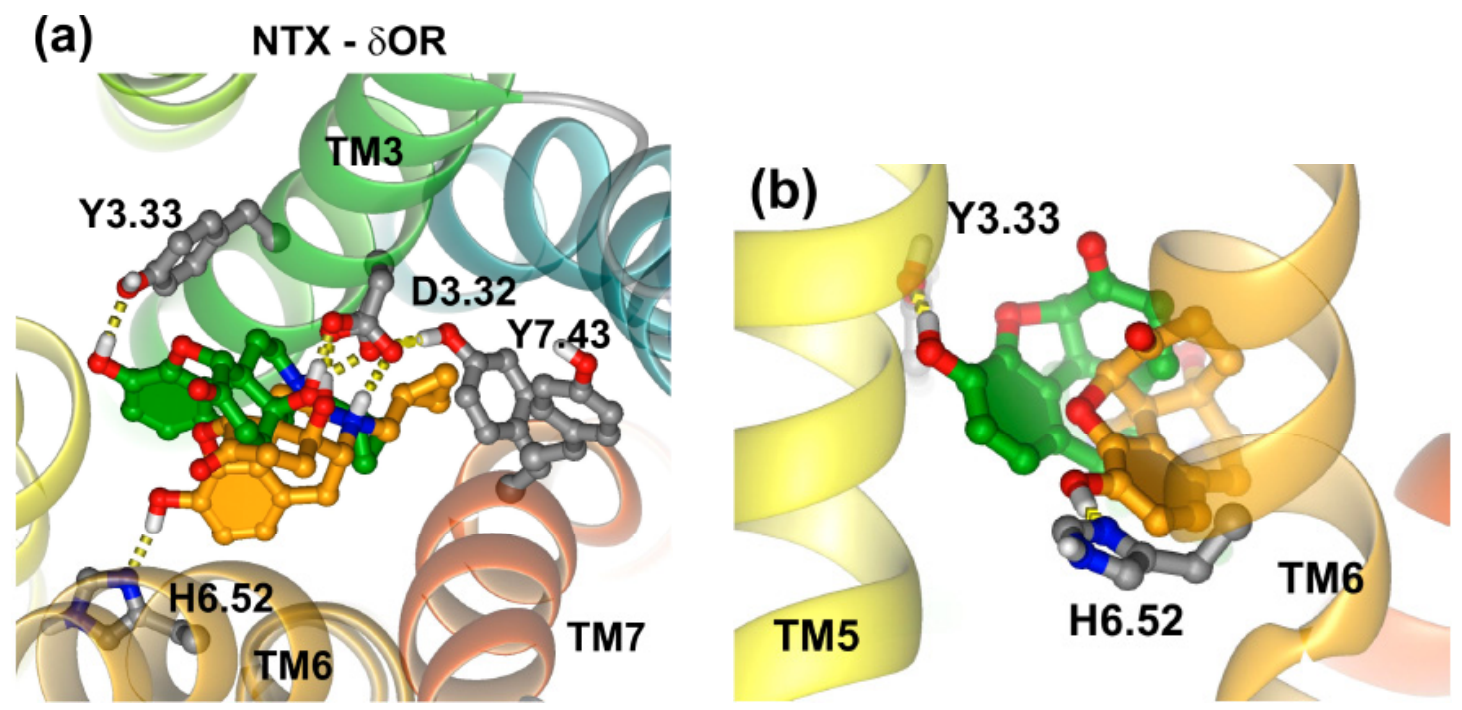

Fig. (6). The structures of NTX- $\delta \mathrm{OR}$ complexes from unrestrained (ligand in green) and restrained (ligand in orange) MD simulations. During the latter simulation the connection between the phenolic OH group of the ligand and H6.52 was restrained. (a) View from the extracellular side. (b) A side view of the same structures.
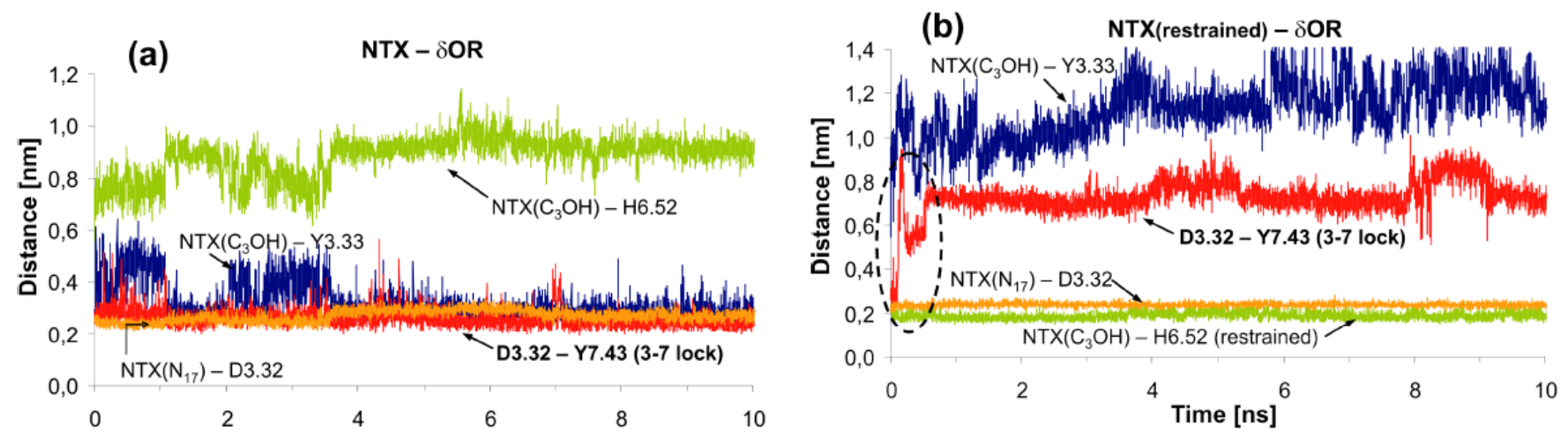

Fig. (7). Plots of distances in the complex NTX- $\delta \mathrm{OR}$ during $10 \mathrm{~ns}$ MD simulations: (a) unrestrained simulation; (b) simulation with a restrained connection between the phenolic OH group $\left(\mathrm{C}_{3} \mathrm{OH}\right)$ of NTX and H6.52. The distance D3.32-Y7.43 is colored in red, NTX $\left(\mathrm{C}_{3} \mathrm{OH}\right)$ Y3.33 in dark blue, NTX $\left(\mathrm{N}_{17}\right)$-D3.32 in orange and NTX $\left(\mathrm{C}_{3} \mathrm{OH}\right)-\mathrm{H} 6.52$ in green. Dashed ellipse indicates breaking of "3-7 lock". 
(a) NTX - $\mathrm{KOR}$

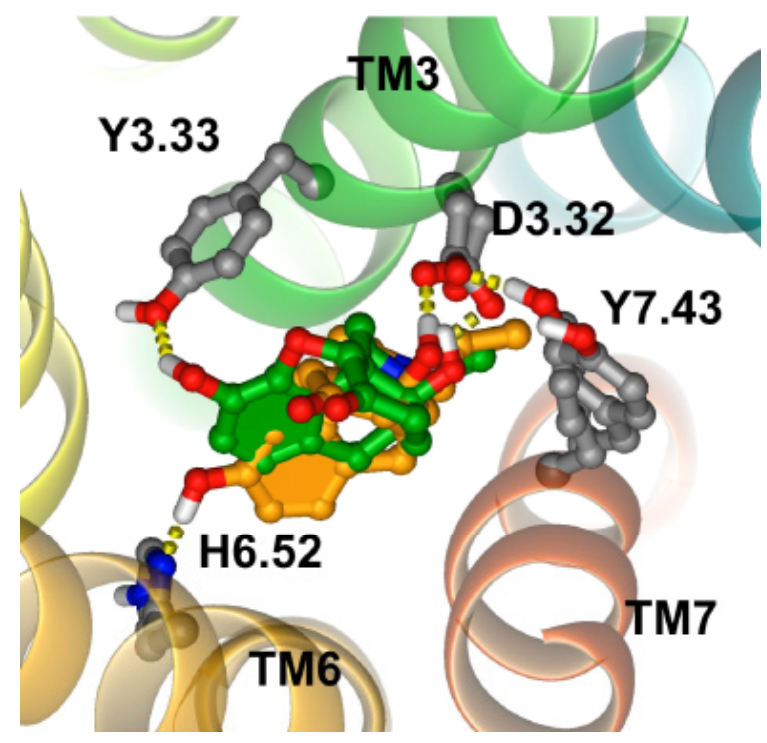

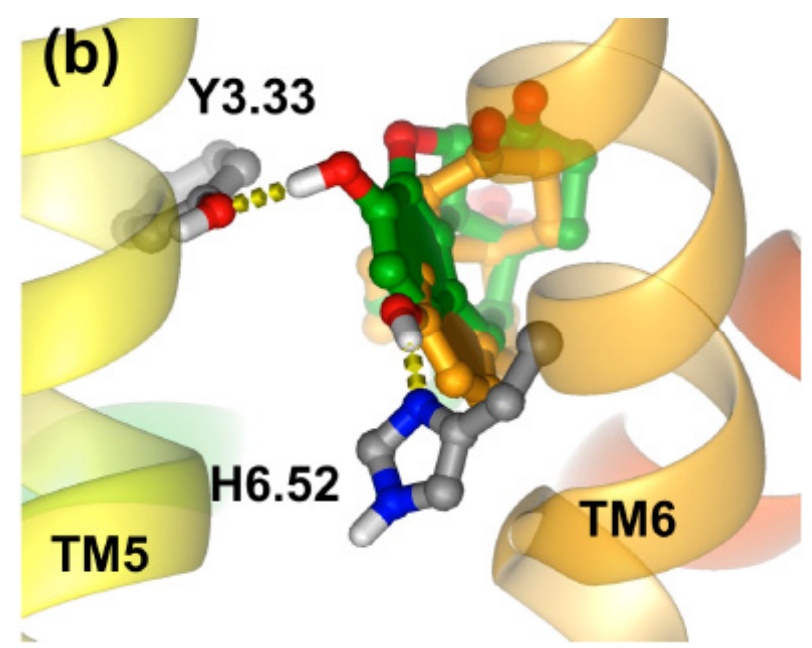

Fig. (8). The structures of NTX-KOR complexes from unrestrained (ligand in green) and restrained (ligand in orange) MD simulations. During the latter simulation the connection between the phenolic OH group of the ligand and H6.52 was restrained. (a) View from the extracellular side. (b) A side view of the same structures.

receptors since, contrary to selective antagonists, it has no "address" part so its motion in the binding site is not hindered by distant parts of the receptor. A harmonic restraint (weak distance restraint $0.2 \mathrm{~nm}$ - the same distance was found in the morphine- $\mu$ OR complex [31]) was imposed on the hydrogen bond between H6.52 and the phenolic $\mathrm{OH}$ group of NTX. The initial position of NTX was taken from the final stage of the unrestrained MD simulation of this ligand in a respective receptor so NTX was initially bound to Y3.33. Stable positions of NTX, unrestrained and restrained superimposed, in complex with $\delta \mathrm{OR}$ are shown in Fig. (6a) and Fig. (6b). Their corresponding MD simulations are shown in Fig. (7a) (unrestrained) and Fig. (7b) (restrained). Accordingly, the structures of NTX-KOR are shown in Fig. (8a) and Fig. (8b) and their MD simulations in Fig. (9a) and Fig. (9b).

The hydrogen bond between the phenolic hydroxyl group of NTX and Y3.33 was stable in both unrestrained simulations. There is an initial instability of the ligand in $\delta \mathrm{OR}$ during the unrestrained simulation (associated with a movement of the ligand between Y3.33 and H6.62) but the $\operatorname{NTX}\left(\mathrm{C}_{3} \mathrm{OH}\right)-\mathrm{Y} 3.33$ hydrogen bond stabilized after $3.5 \mathrm{~ns}$ (Fig. 7a). However, this interaction was lost very shortly after the restrained simulation started (Fig. 7a and Fig. 7b for $\delta O R$, and Fig. 9a and Fig. 9b for $\mathrm{KOR}$ ). Ionic interaction of the charged amine of NTX with D3.32 was stable in all simulations. Although a new hydrogen bond between the phenolic hydroxyl group of NTX and H6.52 was created very rapidly (along the break of an interaction with Y3.33) in both restrained simulations, the "3-7 lock" broke after $100 \mathrm{ps}$ - 200 ps in both complexes. The structure stabilized after about 600 ps for $\delta$ OR (Fig. 7b) but only after about 6 ns for KOR (Fig. 9b). There was a temporary restoration of the " $3-7$ lock" at 6 ns of simulation of the NTX(restr.)-KOR complex but it was immediately broken. Such instability was probably evoked by a change in the position of Y3.33 as indicated by a change in the NTX-Y3.33 distance (Fig. 9b). Fragments of MD simulations of unrestrained and restrained NTX- $\delta \mathrm{OR}$ and NTX-KOR complexes are shown in the supporting material (Animations 6-7, respectively).

\section{Coupling of a Ligand Motion with Disruption of the "3-7 lock"}

Based on different positions of antagonists (bound to TM3) and agonists (bound to TM6 with their phenolic OH group) one can propose the hypothesis about finishing movements of the analyzed ligands in the binding site. Both agonists and antagonists bind to Y3.33 but only agonists (here butorphanol and the restrained NTX mimicking an agonist) are able to rotate and reach $\mathrm{H6.52}$ which is located deeper. However, to validate this hypothesis more agonists have to be investigated. During this movement both Y3.33 and H6.52 may form hydrogen bonds with the phenolic $\mathrm{OH}$ group of an agonist. As a result of this movement the hydrogen bond D3.32-Y7.43 gets broken. Such sequence of events is consistent with the experimental results of Befort $e t$ al. [50] showing that mutations $\mathrm{Y} 3.33 \mathrm{~F}$ and $\mathrm{Y} 3.33 \mathrm{~A}$ reduce binding affinities of antagonists as well as agonists. The agonist may rotate around D3.32 (a position of D3.32 remains the same during rotation of NTX in the binding site see Fig. (6a) and Fig. (8a)) and at the same time penetrates deeper into the receptor structure (Fig. $\mathbf{6 b}$ and Fig. 8b). The large N-moiety of NTX and other antagonists is rotatable so the resulting conformational space of this substituent is rather large, but it did not facilitate breaking of the D3.32Y7.43 connection. This is possibly due to favorable interactions of this part of the ligand with adjacent hydrophobic residues such as M3.36 and W6.48. An additional residue, G7.42, is also located very close to the ligand's N-moiety. A small residue in this position is conserved in opioid receptors and other types of GPCRs. It may help to accommodate relatively large parts of ligands 

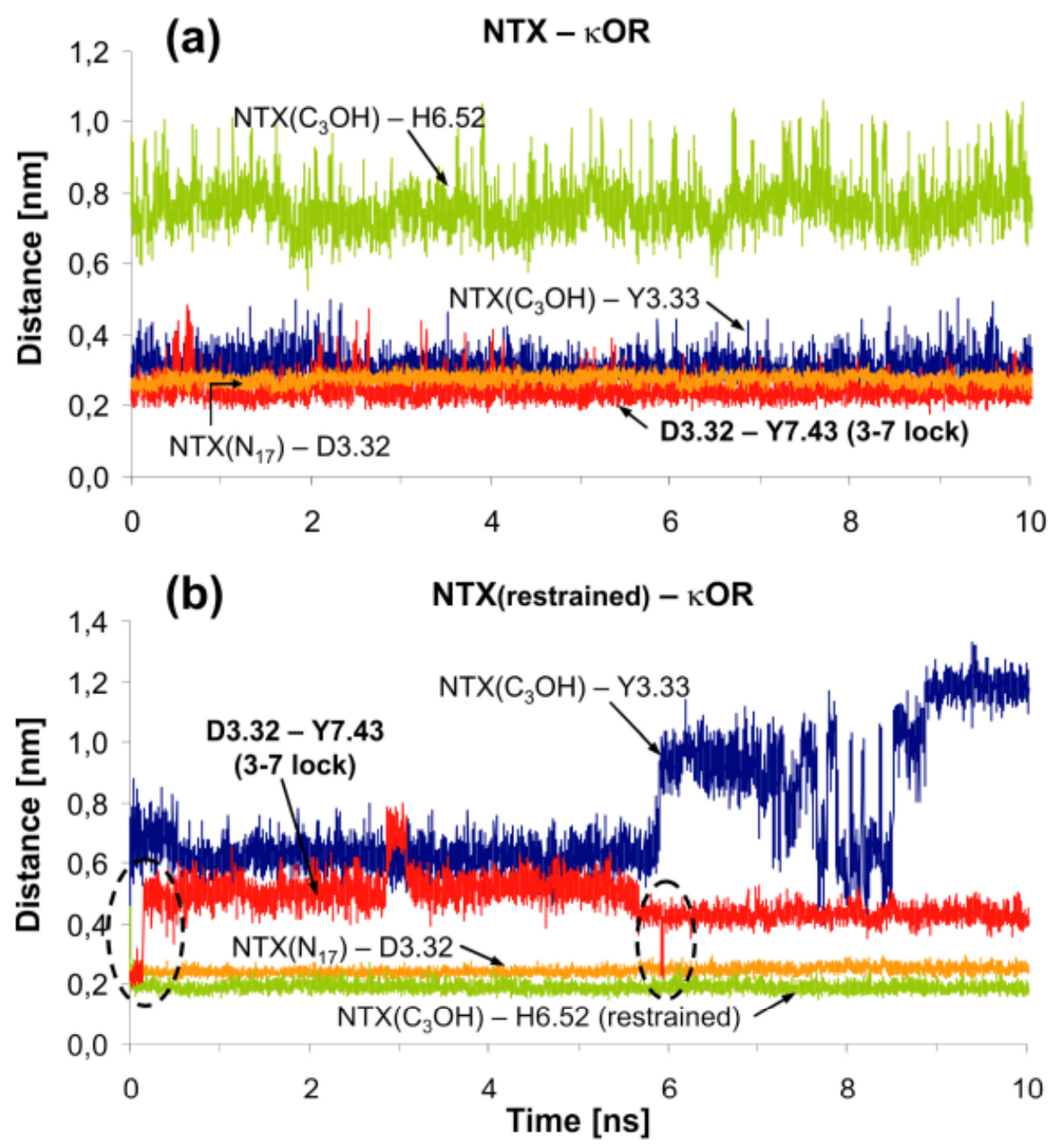

Fig. (9). Plots of distances in the complex NTX-kOR during 10 ns MD simulations: (a) unrestrained simulation; (b) simulation with a restrained connection between the phenolic OH group $\left(\mathrm{C}_{3} \mathrm{OH}\right)$ of NTX and H6.52. The distance D3.32-Y7.43 is colored in red, NTX $\left(\mathrm{C}_{3} \mathrm{OH}\right)$ Y3.33 in dark blue, NTX $\left(\mathrm{N}_{17}\right)-\mathrm{D} 3.32$ in orange and $\mathrm{NTX}\left(\mathrm{C}_{3} \mathrm{OH}\right)-\mathrm{H} 6.52$ in green. Dashed ellipses indicate breaking and temporary restoration of "3-7 lock".

and in this way may protect the "3-7 lock" from breaking. Thus, only the movement of a ligand more deeply into the binding site (from Y3.33 to H6.52 in opioid receptors) can activate this switch.

A nanosecond timescale used in conducted simulations (maximally $21 \mathrm{~ns}$ for a single simulation) is small compared to the activation time of the receptor (which requires milliseconds for full activation). However, we investigated only the action of specific switches and the ligands were already located in the binding site so the usage of such timescale is justified. According to Yan et al. [51] metarhodopsin II (form of rhodopsin able to activate transducin) is formed within miliseconds, however, the preceding intermediates require a shorter time to form: metarhodopsin I - about $10 \mu \mathrm{s}$, lumirhodopsin - about 150 ns, and bathorodopsin about 200 fs only (time of isomerization of retinal). Analogical intermediates, with an additional effect on ligand binding rather than isomerization, are expected to exist for other GPCRs. Changes in protein structure involving large structural rearrangements are slow but the individual motions, especially those involving breaking of single bonds or a conformational change of a single amino acid (such motions constitute action of switches) are rather fast and can be effectively investigated by molecular dynamics simulations even in a nanosecond timescale. The action of switches are then followed by large and much slower rearrangements of protein structure.

\section{Action of the Rotamer Toggle Switch and Time Dependence between Two Switches}

It was proposed $[3,52]$ that the $\mathrm{CWxPxF}$ motif on TM6 participates in a rotamer toggle switch in $\beta_{2} \mathrm{AR}$. Correlated motion of two residues, W6.48 and F6.52, in this receptor initiates a change in the shape of TM6 by increasing the bending angle (linearization) of TM6 at P6.50. Rotamer change of W6.48 and F6.52 and straightening of TM6 were observed during short 900 ps MD simulation with distance restraints leading to an activated state of the histamine $\mathrm{H}_{1}$ receptor [53]. The W6.48/F6.52 switch induced also a conformational change in $\mathrm{F} 6.44$, so the authors proposed existence of a larger F6.44/W6.48/F6.52 rotamer toggle switch. Spontaneous rotamer change of W6.48 was observed 
during MD simulation with no constraints of unliganded adenosine $A_{3}$ receptor (activation of this switch lasted about one nanosecond) as well as of its complex with an agonist (rotamer changed after about $2 \mathrm{~ns}$ and the switch continued to be activated) [54]. For the cannabinoid $\mathrm{CB}_{1}$ receptor another type of rotamer toggle switch composed of W6.48 and located opposite F3.36 (which has an aromatic stacking interaction with W6.48) was proposed [55].

During simulation of the butorphanol- $\kappa \mathrm{OR}$ complex we observed a concerted motion of residues W6.48 and H6.52. The $\chi_{1}$ and $\chi_{2}$ angles of both residues were measured and they are shown in Fig. (10). There is a sudden change of both torsional angles of W6.48 after about 3.5 ns of simulation and a subsequent slower conformational change of H6.52. This histidine residue is bound to the phenolic $\mathrm{OH}$ group of butorphanol during the whole simulation so the change of its conformation initiated by the tryptophan residue is hampered by the ligand. Eventually the rotamer of H6.52 is changed but at a slower rate. W6.48 changes its conformation in less than 2 ps (frequency of coordinates saving) and H6.52 in about 500 ps. This is the first observation of a concerted motion of $\mathrm{W} 6.48$ and $\mathrm{H} 6.52$ in opioid receptors. Analogously to the $\mathrm{CWxPxF}$ rotamer toggle switch in $\beta_{2} \mathrm{AR}$ one can identify the $\mathrm{CWxPxH}$ switch in opioid receptors so that a similar activation scheme may be envisaged for agonists in both receptors. The action of the rotamer toggle switch occurred after the "3-7 lock" was broken and stayed in this position for about $1.5 \mathrm{~ns}$ (Fig. 5b). This observation is very similar to that made by us for the complex of $\mu \mathrm{OR}$ [31]. The action of the rotamer toggle switch occurred after the same time (1.5 ns) following the break of the "3-7 lock" in the NTX(restr.)- $\mu$ OR complex. Therefore, one can propose a kind of time dependence or interdependence between these two switches in opioid receptors. The break of the "3-7 lock" is affecting the conformation of the nearby located ligand. Then, after rearrangement of the ligand structure (what

\section{Action of molecular switch $\mathrm{CWxP}_{(6.50)} \times \mathrm{H}$}
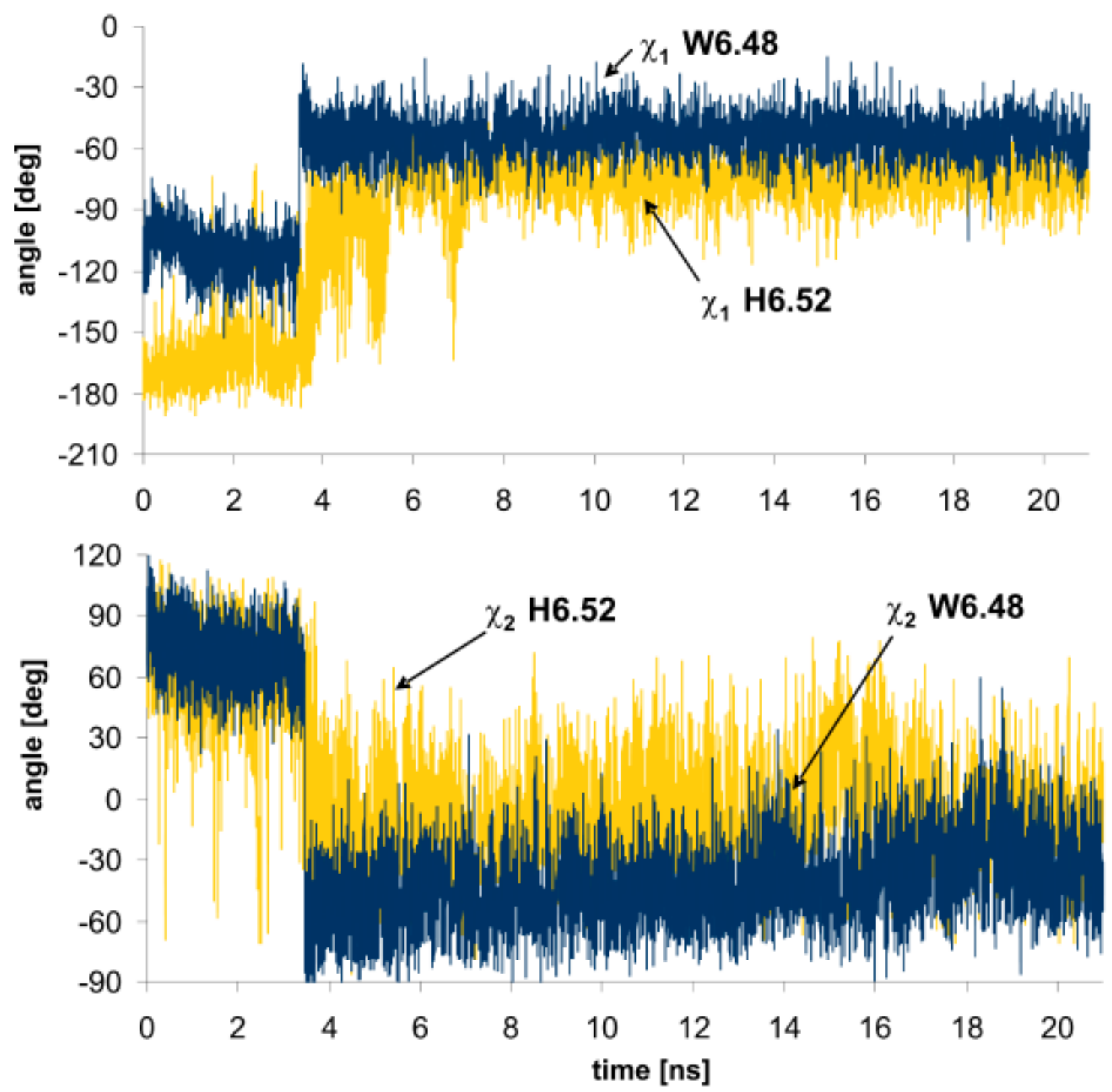

Fig. (10). Plots from the $21 \mathrm{~ns}$ MD simulation of the butorphanol-KOR complex showing $\chi_{1}$ and $\chi_{2}$ angles of W6.48 and H6.52 residues illustrating simultaneous change of their rotamers. 
requires some time - $1.5 \mathrm{~ns}$ in this case), the ligand starts to exert a steric pressure on W6.48 or H6.52 initiating a joint rotameric change of both these residues. Because a change of W6.48 conformation occurs earlier than that of H6.52 (Fig. 10) then probably the tryptophan residue initiates toggling this switch despite a direct binding of H6.52 to the agonist.

We did not observe any rotameric change of W6.48 during simulations of other complexes of $\delta \mathrm{OR}$ and $\kappa \mathrm{OR}$ possibly because of using the simulated annealing procedure prior to MD simulations. Therefore, the initial states of the complexes were dissimilar. Observing the actions of both switches in one simulation requires an appropriate initial state of the complex and much longer MD simulations. We did not observe a conformational change of F6.44 which is conserved in all aligned sequences (Fig. 1 in the supporting material) of GPCRs. Although it is tempting to presume that this residue might be a part of a toggle switch also in opioid receptors (it forms a line with W6.48 and H6.52) additional data are required to explore this possibility.

\section{Influence of Ligands on a Signaling Pathway of the Receptor}

Results obtained from simulations with the restrained $\operatorname{NTX}\left(\mathrm{C}_{3} \mathrm{OH}\right)-\mathrm{H} 6.52$ bond strengthen our earlier hypothesis [31] that such docking mode (to H6.52) is correct for the analyzed agonists (based on tyramine structure) but not for antagonists and that such binding mode can alter the inactive conformation of the receptor and lead to the subsequent steps of receptor activation. It was found $[56,57]$ that mutation of the key residue H6.52 to glutamine or asparagine converts antagonists and inverse agonists (with structure based on tyramine scaffold) into agonists of $\mu \mathrm{OR}$. The flexible side chains of glutamine and asparagine may weaken the hydrogen bond between antagonist's phenolic OH group and Y3.33 and induce a movement of the ligand toward the mutated amino acid. This finally leads to disruption of the D3.32-Y7.43 hydrogen bond and possibly allows for subsequent activation steps.

Receptor signaling via activation of a $G$ protein requires the "ionic lock" to be in an open state as it was found in structures of the recently crystallized opsin [58] and also in the complex of opsin with the C-terminal fragment of the $G_{\alpha}$ subunit [59]. In these structures TM6 is moved out of the center of rhodopsin to form a binding site for a $G$ protein (transducin). This switch is also open in structures of other crystallized GPCRs: $\beta_{1} \mathrm{AR}, \beta_{2} \mathrm{AR}$ and $\mathrm{A}_{2 \mathrm{a}} \mathrm{R}$, but helix TM6 is not displaced to such an extent as in opsin. There is a distinct difference between rhodopsin and other crystallized GPCRs in position of the cytoplasmic loop ICL2, which is exposed outside of the transmembrane bundle in the rhodopsin structure but located inside in other receptors possibly blocking the binding of a $\mathrm{G}$ protein. It may suggest that the crystal structures of $\beta_{1} A R, \beta_{2} A R$ and $A_{2 a} R$ are already activated to some extent. Additionally, it has also been proposed for $\beta_{2} \mathrm{AR}$ [7] that such altered structure allows for signaling via arrestin. The tyrosine residue present in ICL2 (Y3.60) interacts with TM6 in $\beta_{2} \mathrm{AR}$ (or TM3 in $\beta_{1} \mathrm{AR}$ and $\mathrm{A}_{2 \mathrm{a}} \mathrm{R}$ ) and disrupts the "ionic lock". This residue is not present in ICL2 of opioid receptors. There are, however, other interactions in opioid receptors which can also block signal transmission to a $\mathrm{G}$ protein. These interactions were identified by us in the structures of empty $\delta \mathrm{OR}$ and $\kappa \mathrm{OR}$ based on the $\beta_{2} \mathrm{AR}$ template during MD simulations: the aspartic acid residue in ICL2 (D3.62) interacted with T2.39 and, simultaneously, another interaction was formed namely that between D3.49 (from DRY motif) and Y2.42 on helix TM2 in both $\delta \mathrm{OR}$ and $\kappa O R$. In the case of opioid receptor models based on the rhodopsin template the D3.62 residue in ICL2 did not interact with residues on transmembrane helices and loops. The "ionic lock" was closed in both models as in the inactive rhodopsin structure allowing for classical $\mathrm{G}$ protein signaling at subsequent activation stages.

The structures of opioid receptors based on the $\beta_{2} \mathrm{AR}$ template may be used in successive investigations of the initial activation steps in opioid receptors engaged in the arrestin signaling pathway. It was shown that some ligands (fentanyl for $\mu \mathrm{OR}[60]$ and $U 50,488$ for $\kappa O R$ [61]) force this kind of signaling in opioid receptors. Furthermore, Rozenfeld et al. [62] reported arrestin mediated signaling by $\mu \mathrm{OR}-\delta \mathrm{OR}$ heterodimers. The possibility of dual signaling in opioid receptors depending on the kind of a bound ligand makes investigations of activation steps very interesting but also challenging.

\section{CONCLUSIONS}

We investigated complexes of $\delta \mathrm{OR}$ and $\kappa \mathrm{OR}$ opioid receptors with ligands using homology modeling, simulated annealing and molecular dynamics in the membrane environment. Based on obtained results we proposed the finishing movements of the opioid receptor ligands carrying the tyramine structural motif in the binding site. All studied ligands interacted with D3.32, but whereas the antagonist's phenolic $\mathrm{OH}$ group tended to bind Y3.33 that of the agonist moved deeper into the receptor to interact with H6.52. Movement from Y3.33 to H6.52 induced breaking of the " 3 7 lock" (the hydrogen bond D3.32-Y7.43) in the case of an agonist (butorphanol) as well as in the case of a restrained antagonist (NTX). Movement of a ligand from Y3.33 to H6.52 may be regarded as an agonist/antagonist sensor but additional theoretical and experimental investigations are required to verify this hypothesis. Validation of the observed actions of both switches, "3-7 lock" and rotamer toggle switch, followed by checking their interdependence also requires new simulations and experiments. Such investigations should certainly involve additional ligands but also appropriate mutants of opioid receptors. Mutations involving key residues Y3.33 and H6.52 (proposed as important for binding antagonists and agonists) as well as D3.32 and Y7.43 (constituting the " $3-7$ lock") would be needed to investigate the coupling of ligand binding modes with the action of molecular switches. However, all these effects should be carefully interpreted because of the possibility of dual signaling of opioid receptors mediated either by $G$ protein or arrestin.

\section{ABBREVIATIONS \\ $\beta_{2} \mathrm{AR}=\beta_{2}$ adrenergic receptor \\ $\delta \mathrm{OR}=\delta$ opioid receptor}




$$
\begin{aligned}
& \text { KOR }=\text { opioid receptor } \\
& \text { GPCR }=\text { G protein coupled receptor } \\
& \text { MD }=\text { Molecular dynamics } \\
& \text { norBNI }=\text { Norbinaltorphimine } \\
& \text { NTI }=\text { Naltrindole } \\
& \text { NTX }=\text { Naltrexone } \\
& \text { PDB }=\text { Protein data bank } \\
& \text { Rh }=\text { Rhodopsin } \\
& \text { RMSD }=\text { Root mean square displacement } \\
& \text { TM }=\text { Transmembrane domain }
\end{aligned}
$$

\section{ACKNOWLEDGEMENT}

The work was supported by the Polish Ministry of Science and Higher Education (Grants no. N N301 203833 and N N401 1401 33). M. Kolinski acknowledges the School of Molecular Medicine for stipend supporting his PhD study. Discovery Studio was used in country-wide license via ICM Computer Centre, Warsaw University, Poland.

\section{SUPPLEMENTARY MATERIAL}

Supplementary material is available on the publishers Web site along with the published article.

\section{REFERENCES}

[1] Kobilka BK, Deupi X. Conformational complexity of G-proteincoupled receptors. Trends Pharmacol Sci 2007; 28: 397-406.

[2] Kobilka BK. G protein coupled receptor structure and activation. Biochim Biophys Acta 2007; 1768: 794-807.

[3] Lei S, Liapakis G, Xu R, Guarnieri F, Ballesteros JA, Javitch JA. $\beta(2)$ adrenergic receptor activation - Modulation of the proline kink in transmembrane 6 by a rotamer toggle switch. J Biol Chem 2002; 277: 40989-96.

[4] Fritze O, Filipek S, Kuksa V, Palczewski K, Hofmann KP, Ernst OP. Role of the conserved $\operatorname{NPxxY}(\mathrm{x})_{(5,6)} \mathrm{F}$ motif in the rhodopsin ground state and during activation. Proc Natl Acad Sci USA 2003; 100: 2290-5

[5] Porter JE, Hwa J, Perez DM. Activation of the alpha(1b)adrenergic receptor is initiated by disruption of an interhelical salt bridge constraint. J Biol Chem 1996; 271: 28318-23.

[6] Kim JM, Altenbach C, Kono M, Oprian DD, Hubbell WL, Khorana HG. Structural origins of constitutive activation in rhodopsin: Role of the K296/E113 salt bridge. Proc Natl Acad Sci USA 2004; 101: 12508-13.

[7] Audet M, Bouvier M. Insights into signaling from the beta(2)adrenergic receptor structure. Nat Chem Biol 2008; 4: 397-403.

[8] DeWire SM, Ahn S, Lefkowitz RJ, Shenoy SK. beta-arrestins and cell signaling. Annu Rev Physiol 2007; 69: 483-510.

[9] Wisler JW, DeWire SM, Whalen EJ, et al. A unique mechanism of beta-blocker action: Carvedilol stimulates beta-arrestin signaling. Proc Natl Acad Sci USA 2007; 104: 16657-62.

[10] Palczewski K, Kumasaka T, Hori T, et al. Crystal structure of rhodopsin: A G protein-coupled receptor. Science 2000; 289: 73945.

[11] Warne T, Serrano-Vega MJ, Baker JG, et al. Structure of a beta(1)adrenergic G-protein-coupled receptor. Nature 2008; 454: 486-91.

[12] Cherezov V, Rosenbaum DM, Hanson MA, et al. High-resolution crystal structure of an engineered human beta(2)-adrenergic G protein-coupled receptor. Science 2007; 318: 1258-65.
Rosenbaum DM, Cherezov V, Hanson MA, et al. GPCR engineering yields high-resolution structural insights into beta(2)adrenergic receptor function. Science 2007; 318: 1266-73.

Rasmussen SGF, Choi HJ, Rosenbaum DM, et al. Crystal structure of the human beta(2) adrenergic G-protein- coupled receptor. Nature 2007; 450: 383-7.

Jaakola VP, Griffith MT, Hanson MA et al. The 2.6 Angstrom crystal structure of a human $\mathrm{A}(2 \mathrm{~A})$ adenosine receptor bound to an antagonist. Science 2008; 322: 1211-7.

Schioth HB, Fredriksson R. The GRAFS classification system of G-protein coupled receptors in comparative perspective. Gen Comp Endocrinol 2005; 142: 94-101.

Dreborg S, Sundstrom G, Larsson TA, Larhammar D. Evolution of vertebrate opioid receptors. Proc Natl Acad Sci USA 2008; 105: 15487-92.

Waldhoer M, Bartlett SE, Whistler JL. Opioid receptors. Annu Rev Biochem 2004; 73: 953-90.

Corbett AD, Henderson G, McKnight AT, Paterson SJ. 75 years of opioid research: the exciting but vain quest for the Holy Grail. Br J Pharmacol 2006; 147: S153-S62.

[20] Kane BE, Svensson B, Ferguson DM. Molecular recognition of opioid receptor ligands. AAPS J 2006; 8: E126-E37.

[21] Milligan G, Ramsay D, Pascal G, Carrillo JJ. GPCR dimerisation. Life Sci 2003; 74: 181-8.

[22] Vilardaga JP, Nikolaev VO, Lorenz K, Ferrandon S, Zhuang Z, Lohse MJ. Conformational cross-talk between alpha2A-adrenergic and mu-opioid receptors controls cell signaling. Nat Chem Biol 2008; 4: 126-31.

[23] Waldhoer M, Fong J, Jones RM, et al. A heterodimer-selective agonist shows in vivo relevance of $\mathrm{G}$ protein-coupled receptor dimers. Proc Natl Acad Sci USA 2005; 102: 9050-5.

[24] Lunzer MM, Portoghese PS. Selectivity of delta- and kappa-opioid ligands depends on the route of central administration in mice. J Pharmacol Exp Ther 2007; 322: 166-71.

[25] Filipek S, Teller DC, Palczewski K, Stenkamp R. The crystallographic model of rhodopsin and its use in studies of other $\mathrm{G}$ protein-coupled receptors. Annu Rev Biophys Biomol Struct 2003; 32: 375-97.

[26] Fanelli F, De Benedetti PG. Computational Modeling approaches to structure-function analysis of $\mathrm{G}$ protein-coupled receptors. Chem Rev 2005; 105: 3297-351.

[27] Iadanza M, Holtje M, Ronsisvalle G, Holtje HD. kappa-opioid receptor model in a phospholipid bilayer: Molecular dynamics simulation. J Med Chem 2002; 45: 4838-46.

[28] Metzger TG, Paterlini MG, Portoghese PS, Ferguson DM Application of the message-address concept to the docking of naltrexone and selective naltrexone-derived opioid antagonists into opioid receptor models. Neurochem Res 1996; 21: 1287-94.

[29] Aburi M, Smith PE. Modeling and simulation of the human delta opioid receptor. Protein Sci 2004; 13: 1997-2008.

[30] Pogozheva ID, Przydzial MJ, Mosberg HI. Homology modeling of opioid receptor-ligand complexes using experimental constraints. AAPS J 2005; 7: E434-E48.

[31] Kolinski M, Filipek S. Molecular dynamics of mu opioid receptor complexes with agonists and antagonists. Open Struct Biol J 2008; 2: 8-20.

[32] Ballesteros JA, Weinstein H. Integrated methods for the construction of three-dimensional models and computational probing of structure-function relations in $G$ protein-coupled receptors. Methods Neurosci 1995; 25: 366-428.

[33] Portoghese PS, Sultana M, Takemori AE. Design of peptidomimetic delta opioid receptor antagonists using the message-address concept. J Med Chem 1990; 33: 1714-20.

[34] Okada T, Sugihara M, Bondar AN, Elstner M, Entel P, Buss V. The retinal conformation and its environment in rhodopsin in light of a new 2.2 angstrom crystal structure. J Mol Biol 2004; 342: 571-83.

[35] Thompson JD, Higgins DG, Gibson TJ. CLUSTAL W: improving the sensitivity of progressive multiple sequence alignment through sequence weighting, position-specific gap penalties and weight matrix choice. Nucleic Acids Res 1994; 22: 4673-80.

[36] Reynolds KA, Katritch V, Abagyan R. Identifying conformational changes of the beta(2) adrenoceptor that enable accurate prediction of ligand/receptor interactions and screening for GPCR modulators. J Comput Aided Mol Des 2009; 23: 273-88. 
[37] Sali A, Potterton L, Yuan F, vanVlijmen H, Karplus M. Evaluation of comparative protein structure modeling by MODELLER. Proteins 1995; 23: 318-26.

[38] Sanchez R, Sali A. Evaluation of comparative protein structure modeling by MODELLER-3. Proteins 1997: (Suppl 1): 50-8.

[39] Van der Spoel D, Lindahl E, Hess B, Groenhof G, Mark AE, Berendsen HJC. GROMACS: Fast, flexible, and free. J Comput Chem 2005; 26: 1701-18.

[40] Berger O, Edholm O, Jahnig F. Molecular dynamics simulations of a fluid bilayer of dipalmitoylphosphatidylcholine at full hydration, constant pressure, and constant temperature. Biophys J 1997; 72: 2002-13.

[41] van der Spoel D, van Maaren PJ, Berendsen HJC. A systematic study of water models for molecular simulation: Derivation of water models optimized for use with a reaction field. J Chem Phys 1998; 108: 10220-30.

[42] Darden T, York D, Pedersen L. Particle mesh Ewald: An N·log(N) method for Ewald sums in large systems. J Chem Phys 1993; 98 : 10089-92.

[43] Hess B, Bekker H, Berendsen HJC, Fraaije J. LINCS: A linear constraint solver for molecular simulations. J Comput Chem 1997; 18: 1463-72.

[44] Laskowski RA, MacArthur MW, Moss DS, Thornton JM. PROCHECK: A program to check the stereochemical quality of protein structures. J Appl Crystallogr 1993; 26: 283-91.

[45] Morris AL, MacArthur MW, Hutchinson EG, Thornton JM. Stereochemical quality of protein structure coordinates. Proteins 1992; 12: 345-64.

[46] Bayly CI, Cieplak P, Cornell WD, Kollman PA. A well-behaved electrostatic potential based method using charge restraints for deriving atom-centered charges: the RESP model. J Phys Chem 1993; 97: 10269-80.

[47] Krieger E, Darden T, Nabuurs SB, Finkelstein A, Vriend G. Making optimal use of empirical energy functions: Force-field parameterization in crystal space. Proteins 2004; 57: 678-83.

[48] Humphrey W, Dalke A, Schulten K. VMD: Visual molecular dynamics. J Mol Graph 1996; 14: 33-8.

[49] Huber T, Menon S, Sakmar TP. Structural basis for ligand binding and specificity in adrenergic receptors: Implications for GPCRtargeted drug discovery. Biochemistry 2008; 47: 11013-23.
[50] Befort K, Tabbara L, Kling D, Maigret B, Kieffer BL. Role of aromatic transmembrane residues of the delta-opioid receptor in ligand recognition. J Biol Chem 1996; 271: 10161-8.

[51] Yan ECY, Kazmi MA, Ganim Z, et al. Retinal counterion switch in the photoactivation of the $\mathrm{G}$ protein-coupled receptor rhodopsin. Proc Natl Acad Sci USA 2003; 100: 9262-7.

[52] Elling CE, Frimurer TM, Gerlach LO, Jorgensen R, Holst B, Schwartz TW. Metal ion site engineering indicates a global toggle switch model for seven-transmembrane receptor activation. J Biol Chem 2006; 281: 17337-46.

[53] Strasser A, Wittmann HJ. Analysis of the activation mechanism of the guinea-pig Histamine H-1-receptor. J Comput Aided Mol Des 2007; 21: 499-509.

[54] Hallmen C, Wiese M. Molecular dynamics simulation of the human adenosine $\mathrm{A}(3)$ receptor: agonist induced conformational changes of Trp243. J Comput Aided Mol Des 2006; 20: 673-84.

[55] McAllister SD, Hurst DP, Barnett-Norris J, Lynch D, Reggio PH, Abood ME. Structural mimicry in class A G protein-coupled receptor rotamer toggle switches - The importance of the F3.36(201)/W6.48(357) interaction in cannabinoid CB1 receptor activation. J Biol Chem 2004; 279: 48024-37.

[56] Spivak CE, Beglan CL, Seidleck BK, et al. Naloxone activation of mu-opioid receptors mutated at a histidine residue lining the opioid binding cavity. Mol Pharmacol 1997; 52: 983-92.

[57] Spivak CE, Beglan CL, Zollner C, Surratt CK. betafunaltrexamine, a gauge for the recognition site of wildtype and mutant H297Q mu-opioid receptors. Synapse 2003; 49: 55-60.

[58] Park JH, Scheerer P, Hofmann KP, Choe HW, Ernst OP. Crystal structure of the ligand-free G-protein-coupled receptor opsin. Nature 2008; 454: 183-8.

[59] Scheerer P, Park JH, Hildebrand PW, et al. Crystal structure of opsin in its G-protein-interacting conformation. Nature 2008; 455: 497-502.

[60] Macey TA, Lowe JD, Chavkin C. Mu opioid receptor activation of ERK1/2 is GRK3 and arrestin dependent in striatal neurons. J Biol Chem 2006; 281: 34515-24.

[61] Bruchas MR, Macey TA, Lowe JD, Chavkin C. Kappa opioid receptor activation of $\mathrm{p} 38$ MAPK is GRK3-and arrestin-dependent in neurons and astrocytes. J Biol Chem 2006; 281: 18081-9.

[62] Rozenfeld R, Devi LA. Receptor heterodimerization leads to a switch in signaling: beta-arrestin2-mediated ERK activation by mudelta opioid receptor heterodimers. FASEB J 2007; 21: 2455-65.

(C) Kolinski and Filipek; Licensee Bentham Open.

This is an open access article licensed under the terms of the Creative Commons Attribution Non-Commercial License (http://creativecommons.org/ licenses/by-nc/3.0/), which permits unrestricted, non-commercial use, distribution and reproduction in any medium, provided the work is properly cited. 